\title{
Fast and furious: Early differences in growth rate drive short-term plant dominance and exclusion under eutrophication
}

\author{
Zhang Pengfei ${ }^{1}$, Mariet Hefting ${ }^{2}$, Merel Soons ${ }^{2}$, George Kowalchuk ${ }^{2}$, Mark Rees ${ }^{3}$, Andrew \\ Hector $^{4}$, Lindsay Turnbull ${ }^{5}$, Xiaolong Zhou ${ }^{6}$, Zhi Guo ${ }^{1}$, Chengjin Chu ${ }^{7}$, Guozhen Du ${ }^{1}$, and \\ Yann Hautier ${ }^{8}$ \\ ${ }^{1}$ Lanzhou University \\ ${ }^{2}$ Utrecht University \\ ${ }^{3}$ Sheffield University \\ ${ }^{4}$ University of Oxford \\ ${ }^{5}$ Oxford University \\ ${ }^{6}$ Xinjiang University \\ ${ }^{7}$ Sun Yat-Sen University \\ ${ }^{8}$ Universiteit Utrecht
}

May 5, 2020

\begin{abstract}
1. The reduction of plant diversity following eutrophication threatens many ecosystems worldwide. Yet, the mechanisms by which species are lost following nutrient enrichment are still not completely understood, nor are the details of when such mechanisms act during the growing season, which hampers understanding and the development of mitigation strategies. 2 . Using a common garden competition experiment, we found that early-season differences in growth rates among five perennial grass species measured in monoculture predicted short-term competitive dominance in pairwise combinations and that this effect was stronger under a fertilisation treatment. 3. We also examined the role of early-season growth rate in determining the outcome of competition along an experimental nutrient gradient in an alpine meadow. Early differences in growth rate between species predicted short-term competitive dominance under both ambient and fertilized conditions and competitive exclusion under fertilized conditions. 4. The results of these two studies suggests that plant species growing faster during the early stage of the growing season gain a competitive advantage over species that initially grow more slowly, and that this advantage is magnified under fertilisation. This finding is consistent with the theory of asymmetric competition for light in which fastgrowing species can intercept incident light and hence outcompete and exclude slower-growing (and hence shorter) species. We predict that the current chronic nutrient inputs into many terrestrial ecosystems worldwide will reduce plant diversity and maintain low biodiversity state by continuously favouring fast-growing species. Biodiversity management strategies should focus on controlling nutrient inputs and reducing the growth of fast-growing species early in the season.
\end{abstract}

\section{Introduction}

Anthropogenic inputs of nutrients, including nitrogen $(\mathrm{N})$ and phosphorus $(\mathrm{P})$, into the biosphere have greatly increased in recent decades and continue to rise (Sinha et al., 2017). This environmental eutrophication represents a major threat to biodiversity in many terrestrial, freshwater and marine ecosystems worldwide, as it is usually associated with biodiversity loss (Borer et al., 2014, Ren et al., 2017). In grasslands, nutrient enrichment, both deliberate (agricultural fertilization) and unintentional (atmospheric deposition), has been shown to have profound impacts on ecosystems (Erisman et al., 2008). Nutrient input usually increases primary productivity and reduces plant diversity and community stability (Midolo et al., 2018, Soons et 
al., 2017). This loss of plant diversity can then impact the functioning of ecosystems and their associated ecosystem services (Hautier et al., 2015, HautierIsbell et al., 2018, Hautier et al., 2014, Hector et al., 2010, Isbell et al., 2015). However, we do not have a complete understanding of the mechanisms by which nutrient inputs lead to the loss of plant diversity (Harpole et al., 2017) or the timing during the growing season when these mechanisms are most important.

In low-fertility grasslands, where soil resources are strongly limiting, diversity is often high. However, resource competition theory ( $R^{*}$ theory) predicts dominance by the single species that can deplete soil resources to the lowest level (with the lowest value of $R^{*}$ ) (Tilman, 1982, Tilman, 1980). We must therefore assume that low-fertility grasslands are either limited by more than one belowground resource (Fay et al., 2015, Hutchinson, 1957), or that additional mechanisms operate, such as negative soil feedbacks, that introduce frequency-dependence and hence stabilisation (Petermann et al., 2008). Coexistence might be made easier in such systems because competition for belowground resources is often assumed to be size-symmetric (Vojtech et al., 2007, HautierVojtech et al., 2018), thus leading to relatively small fitness differences between species, which can be offset by weak niche differentiation (Chesson, 2000).

Under fertilized conditions, when nutrient limitation is alleviated and light becomes the limiting resource, resource competition theory $\left(I^{*}\right.$ theory) again predicts competitive dominance, this time by the species that is able to intercept light and reduce it to the lowest level (Dybzinski and Tilman, 2007, Vojtech et al., 2007). Because light is a directionally supplied resource, tall species can intercept and pre-empt light, making it unavailable to low-growing species. Competition for light is likely to be highly size-asymmetric and might therefore lead to very large fitness differences and hence the exclusion of smaller, slow-growing species (Hautier et al., 2009, DeMalach et al., 2017, Borer et al., 2014) even if the same stabilising niche differences still operate.

While direct measurements of mechanistic plant competition are extremely difficult, relative growth rate (RGR) is relatively easy to measure, and many plant species show striking differences in their relative growth rate, even when grown under similar environmental conditions (Grime and Hunt 1975). High RGR might confer a strong competitive advantage under highly fertile conditions, because it enables a species to quickly capture light and deny it to competitors. But under low-fertility conditions, we might expect high RGR to be a much poorer predictor of competitive outcomes, as other traits, reflecting niche differences, may play a greater role. The timing of growth might also be a key factor in determining competitive outcomes. For example, a species growing faster during the early stage of the growing season might reduce light availability and thus have a disproportionate competitive advantage relative to species that initially grow more slowly. RGR can be measured at different time points and thus be used to identify when during the growing season differences in RGR are particularly important.

We used two studies to test whether early differences in species growth rates better predict short-term competitive dominance under fertilised conditions: (1) a common garden experiment where species were grown in monoculture and in pairwise and five-species mixtures under low and high soil fertility and (2) an experiment in a natural grassland community that also included fertilizer treatments. Critically, both studies provide detailed measurements of aboveground biomass through the growing season. We focus mainly on competitive outcomes in fertilized conditions, where we expect competition to be primarily for light, hence species with high early-season RGR in monoculture should dominate mixtures. We contrast the fertile situation with less productive conditions but because the outcome of competition may be slower, the comparison is limited by the short-term nature of our study.

\section{Material and methods}

\section{Overview}

Our two experiments both measured aboveground plant biomass at regular intervals during the growing season at a relatively uncommon level of temporal detail. From these measurements we could calculate daily RGR per species throughout the growing season, which provides unique insight into growth rates and their temporal changes (in contrast, most studies lack a temporal dimension and measure biomass only at 
harvest). We used these measures of RGR to identify when, during the growing season, differences in RGR best predict competitive outcomes in mixtures, comparing the high and low fertility treatments in each study. The first data set comes from a competition experiment with five European perennial grass species grown under nutrient-limited unproductive and nutrient-rich productive conditions in the experimental garden of the University of Zurich, Switzerland ( $47^{\circ} 23^{\prime} \mathrm{N}, 8^{\circ} 33^{\prime} \mathrm{E}$, and $546 \mathrm{~m}$ height a.s.l.). The second data set lacks independent monocultures but comes from a field experiment in which nitrogen and phosphorus are added alone or in combination to a flat alpine meadow at the Alpine Meadow and Wetland Ecosystems Research

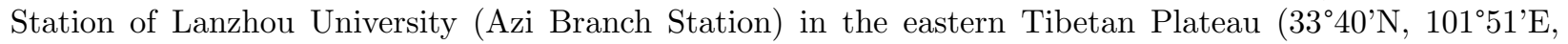
altitude $3500 \mathrm{~m}$ a.s.l.), Gansu, China. The growing season typically starts around April 15 ( day 106) in Zürich and around May 15 ( day 136) in Gansu.

Common garden experiment

Experimental design

The common garden experiment has been described at greater length elsewhere (Vojtech et al., 2008, Vojtech et al., 2007, HautierVojtech et al., 2018). Briefly, we established monocultures ( $\mathrm{n}=5)$, all pairwise mixtures $(\mathrm{n}=10)$ and the full five-species mixtures $(\mathrm{n}=1)$ of five perennial grass species (Poaceae): Alopecurus pratensis L., Anthoxanthum odoratumL., Arrhenatherum elatius (L.) P. Beauv. ex J. Presl \& C. Presl,Festuca rubra ssp. commutata Gaud. (=Festuca nigrescens Lam.), Holcus lanatus L. (Lauber and Wagner, 2001). Each species combination was replicated five times for a total of 80 plots. Species were sown at a target density of 1000 seeds $\mathrm{m}^{-2}$ from seeds of individual species. Plants were established in $1 \mathrm{~m}^{2}$ plots on highly fertile soil (Garden humus, Ricoter, Aarberg, Switzerland). The experiment ran from April 2004 to June 2008. Plots were watered daily and regularly weeded throughout the duration of the experiment. During 2005 and 2006, plants were regularly fertilized with an NPK fertilizer corresponding to $15 \mathrm{~g} \mathrm{~m}^{-2} \mathrm{yr}^{-1}$ of nitrogen to create highly productive conditions. In 2007, we divided the plots into four subplots of 50 x $50 \mathrm{~cm}$ (Fig. S1). In half of these subplots, we maintained the initial highly productive conditions by continuously adding the NPK fertilizer. In the other half of the subplots we reduced soil fertility by a combination of the cessation of fertilization and the addition of sucrose (in five applications of $500 \mathrm{~g} \mathrm{~m}^{-2}$ year $^{-1}$ during 2007 and two applications of $625 \mathrm{~g} \mathrm{~m}^{-2}$ in 2008). Addition of a carbon source limits nutrient availability to plants and reduces productivity due to the immobilisation of nitrogen by soil micro-organisms (Killham, 1994) and increases competition between micro-organisms and plants for nitrate and ammonium (Bardgett et al., 2003; Schmidt et al., 1997). Additionally, we crossed the productivity treatments with regular cutting of the canopy structure to create disturbed conditions (HautierVojtech et al., 2018). Calculating daily RGR per species throughout the growing season for the plots that were disturbed was not possible because of the limited number of samples between each cutting event. Here, we therefore analyse only the undisturbed productive and unproductive conditions.

\section{Data collection}

In mid-June 2008, after two years of treatment, aboveground plant biomass was clipped at soil level in the inner $30 \times 30 \mathrm{~cm}$ of each subplot and sorted to species. To estimate daily RGR of each species in monoculture, aboveground plant biomass was clipped at soil level within $10 \times 10 \mathrm{~cm}$ quadrats in the outer $10 \mathrm{~cm}$ surrounding the inner $30 \times 30 \mathrm{~cm}$ of each subplot during sequential harvests on days $53,67,88,109$, $116,123,130,145,152,162$, and 171 in the year 2008. Day 171 was the peak standing biomass. Each time different randomly chosen quadrats were clipped (Fig. S1). Harvested biomass samples were dried at $80^{\circ} \mathrm{C}$ and weighed. Soil cores were collected regularly during the growth season in 2008 and analysed for nitrate and ammonium concentrations (Labor für Boden- und Umweltanalytik, Thun, Switzerland). We measured plot level light interception ability in monoculture for each species and each nutrient treatment before the harvest in end-April 2008 as the percentage of transmitted photosynthetically active radiation (PAR) reaching the soil surface.

Field experiment

Experimental design 
The field experiment was set up in April 2011 and has been described elsewhere (Zhang et al., 2015, Zhou et al., 2017, Zhou et al., 2018). Large herbivores were excluded between March and October by fencing the experimental area. A homogeneous area of meadow covering $230 \times 100 \mathrm{~m}$ was divided into four parts that were given N, P, their combination or neither. Six plots, each $10 \times 20 \mathrm{~m}$, were established within each nutrient area. Fertilization treatments consisted of a factorial combination of $\mathrm{N}$ and $\mathrm{P}$ addition applied annually to fertilized plots in each of three blocks: N, P and NP. Nitrogen was supplied at a rate $15 \mathrm{gN}$ $\mathrm{m}^{-2} \mathrm{y}^{-1}$, phosphorus at a rate of $8 \mathrm{gP} \mathrm{m}^{-2} \mathrm{y}^{-1}$, and nitrogen and phosphorus at a rate of $10 \mathrm{gN} \mathrm{m}^{-2} \mathrm{y}^{-1}$ and $8 \mathrm{gP} \mathrm{m}^{-2} \mathrm{y}^{-1}$. While we acknowledge that plots within each nutrient area are not independent, previous studies have shown that there were no significant differences among them in term of plant species diversity, community biomass and community composition at the start of the experiment (Zhou et al., 2018). N was applied as ammonium nitrate $\left(\mathrm{NH}_{4} \mathrm{NO}_{3}\right)$ and $\mathrm{P}$ as monocalcium phosphate $\left(\mathrm{Ca}\left(\mathrm{H}_{2} \mathrm{PO}_{4}\right)_{2}\right)$ annually at the end of May. Each plot was subsequently divided into two $10 \times 10 \mathrm{~m}$ subplots; one randomly assigned subplot was used to measure aboveground plant biomass through time for twenty common species (Table S1), and the other subplot was used to measure aboveground plant biomass and species composition in early August in one randomly selected $0.5 \times 0.5 \mathrm{~m}$ quadrat.

\section{Data collection}

In 2013, after three years of nutrient addition, in the subplots dedicated to measuring aboveground plant biomass through time, we sampled twenty common species accounting for $85 \pm 10 \%$ of aboveground biomass (Table S1). For each species, we randomly selected, dried at $80^{\circ} \mathrm{C}$ and weighed 12 individuals on days 146 , $157,167,177,197,207,238$, and 254 in the year of 2013. We stopped sampling species once they were in full flower, resulting in a lower number of species sampled after day 177. In the subplots dedicated to measuring aboveground plant biomass and species composition at peak biomass, the vegetation was clipped in mid-August 2013 at soil level in one randomly selected $0.5 \times 0.5 \mathrm{~m}$ quadrat, sorted to species, dried at $80^{\circ} \mathrm{C}$ and weighed.

Statistical analyses

All analyses were done using R 3.5.1 (R Development Core Team, 2018).

\section{Common garden experiment}

In the second year of our common garden experiment, we tested the effect of nutrient treatments on mineral nitrogen available to plants, biomass production, and understory light availability by performing ANOVAtype generalized linear models (McCullagh and Nelder, 1989) since our response include variables with normal and non-normal error distributions. Data that were analysed using normal error distribution included nitrogen available to plants and biomass production. Data with non-normal error distribution included the percentage of understory light availability, which was analysed with a quasibinomial error distribution to control for overdispersion.

To model plant growth, we fitted a four-parameter logistic curve to species biomass data through time (Pinheiro and Bates, 2000, Paine et al., 2012) using a non-linear mixed-effects regression model with the nlme function (Pinheiro and Bates, 2000). This model best fitted plant growth through the season which initially increases, stabilizes and then decreases over time but not necessarily in a symmetric way. Species, nutrient treatments and their interaction were treated as fixed effects and the four parameters of the logistic growth model $\left(K, x m i d, M_{0}\right.$, and $r$ ) were treated as random effects allowing them to vary between species and nutrient treatments. To improve homoscedasticity of the residuals, aboveground biomass was natural log-transformed before analyses giving:

$\log \left(M_{t}\right)=M_{0}+\frac{\left(K-M_{0}\right)}{\frac{1+\exp ((x) i d-t)}{r)}}$ eqn 1

where $t$ is time in days of the year, $M_{t}$ is aboveground plant biomass at time $t ; M_{0}$ is the asymptotic mass ast $\rightarrow-\infty ; K$ is the asymptotic mass ast $\rightarrow \infty$; xmid is the mass at the inflection point, the time at which RGR is maximized and $r$ is a scale parameter. 
RGR is given by $\frac{d\left(\log \left(M_{t}\right)\right)}{\mathrm{dt}}$, thus we estimated daily RGR during the growing season for each species as:

$\mathrm{RGR}_{t}=\frac{\left.\frac{\left(K-M_{0}\right) \exp ((x m i d-t)}{r}\right)}{\frac{r(1+e x p((x m i d-t)}{r)}}{ }^{2}$ eqn 2

Thus, for each species in each nutrient treatment combination, one value for $\mathrm{RGR}_{t}$ was generated for each day between the first and last day of the sequential harvests, yielding 119 values ofRGR $t$ between day 53 and 171.

To assess whether early differences in growth rate between species in monocultures predict short-term competitive dominance at harvest in pairwise and in five-species mixtures under both productive and unproductive conditions, we related the relative differences in species biomass of the harvest of June 2008 for each pairwise mixture and for each combination of pairs in the five-species mixtures to the daily relative differences in growth rates of the respective species and nutrient treatment combination in monoculture, thus generating 119 regressions for each of the pairwise and five-species mixtures, one for each day between day 53 and 171.

Relative difference in abundance at harvest (day 171) in mixtures $\left(\Delta \mathrm{B}_{\mathrm{ij}}\right)$ between species $i$ and $j$ was calculated as the natural $\log$ ratio of differences in biomass as:

$\left(\Delta \mathrm{B}_{\mathrm{ij}}\right)=\operatorname{Ln}\left(\frac{B_{i}}{B_{j}}\right)$ eqn 3

A positive value of relative difference in abundance means that the biomass of species $i$ at harvest is higher than that of species $j$ when growing together, i.e. species $i$ has a greater relative abundance when growing with species $j$, and vice versa. Ten values of relative difference in abundance $\left(\Delta \mathrm{B}_{\mathrm{ij}}\right)$ were calculated for each of the pairwise and five-species mixtures, one for each of the ten combination of pairs of species.

Daily relative differences in growth rates $\left(\Delta \mathrm{P} \mathrm{P}_{t \mathrm{ij}}\right)$ between species $i$ and $j$ were calculated for each day between day 53 and 171 as the natural $\log$ ratio of difference in RGR in monoculture as:

$\left(\Delta \mathrm{P} \mathrm{P}_{t \mathrm{ij}}\right)=\operatorname{Ln}\left(\frac{{\mathrm{P} \Gamma \mathrm{P}_{t i}}_{\mathrm{P}_{j}}}{\mathrm{P}_{t_{j}}}\right)$ eqn 4

A positive value of daily relative differences in growth rates means that the relative growth rate in monoculture at time $t$ of species $i$ is higher than that of species $j$, i.e. species $i$ grow relatively faster than species $j$ at a given day in the year, and vice versa. For each of the ten species pairs, daily relative differences in growth

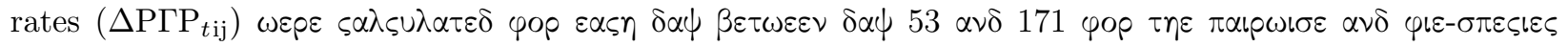
$\mu \xi$ тире५.

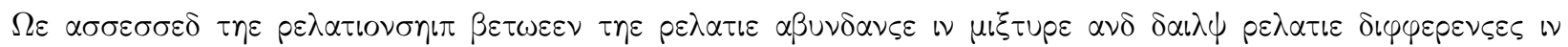

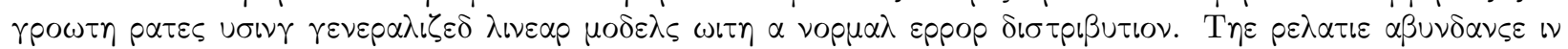

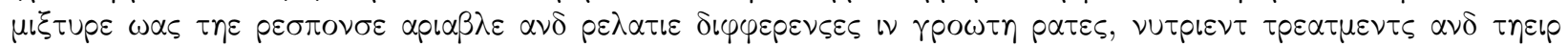

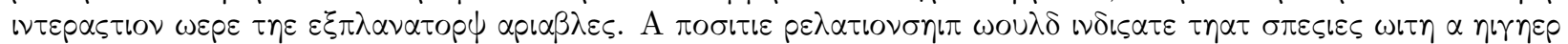

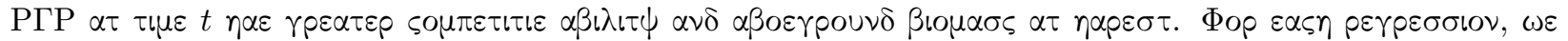
$\varepsilon \xi \tau \rho \varsigma \varsigma \tau \delta \delta ~ \tau \eta \varepsilon ~ \sigma \lambda о \pi \varepsilon ~ \alpha \nu \delta ~ 95 \% ~ " I ~ \alpha \varsigma ~ \omega \varepsilon \lambda \lambda ~ \alpha \varsigma ~ \tau \eta \varepsilon ~ \pi \varepsilon \rho \varsigma \varepsilon \nu \tau \alpha \gamma \varepsilon ~ o \varphi ~ \alpha \rho l \alpha \nu \varsigma \varepsilon \varepsilon \xi \pi \lambda \alpha \iota v \varepsilon \delta\left(\mathrm{P}^{2} \alpha \lambda \cup \varepsilon\right)$.

$\Phi \iota \epsilon \lambda \delta \epsilon \xi \pi \epsilon \rho \imath \epsilon \nu \tau$

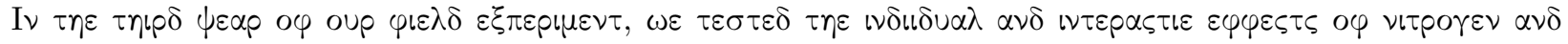

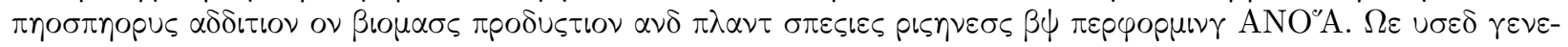

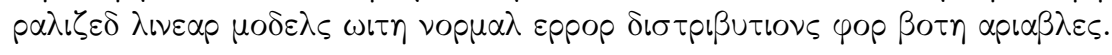

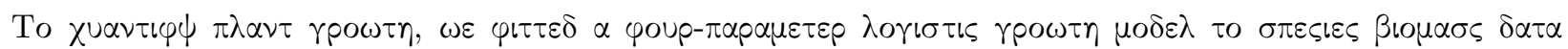

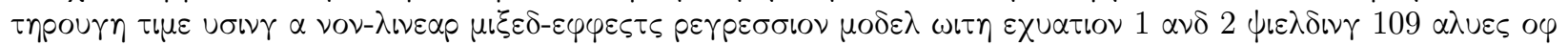
$\mathrm{P} \mathrm{P}_{t} \beta \varepsilon \tau \omega \varepsilon \varepsilon \nu \delta \alpha \psi 146 \alpha \nu \delta 254$.

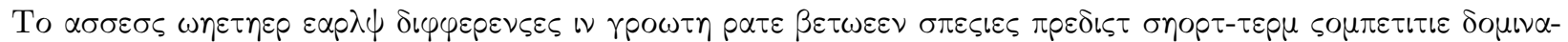

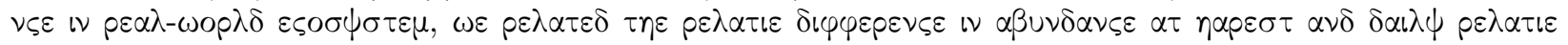

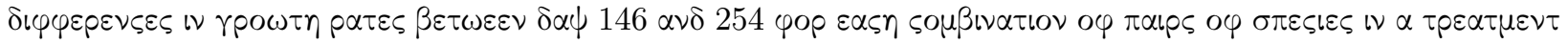

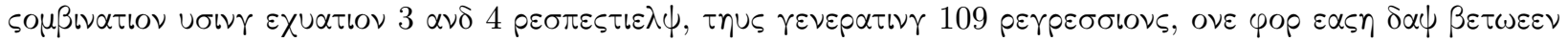




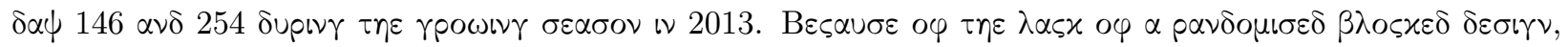

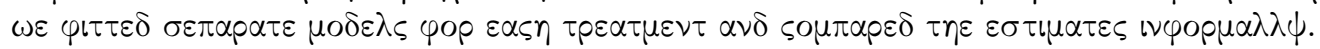

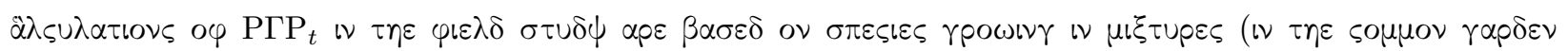

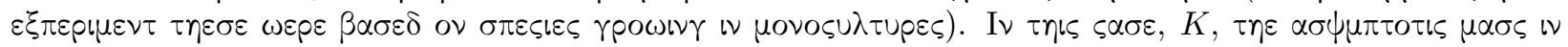

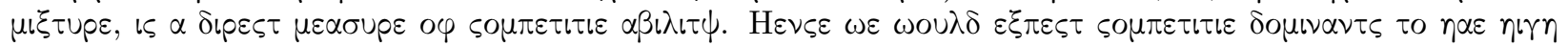

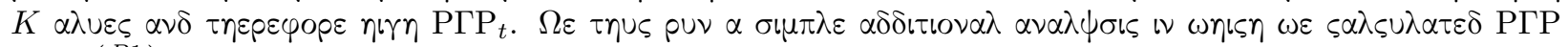

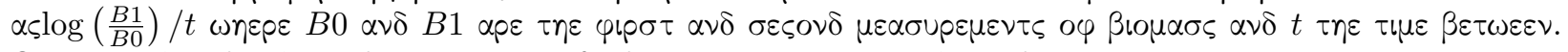

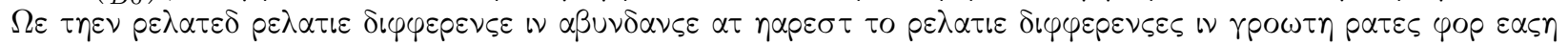

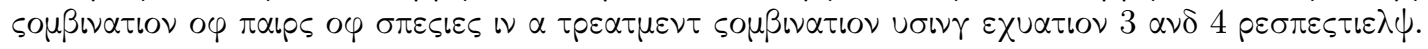

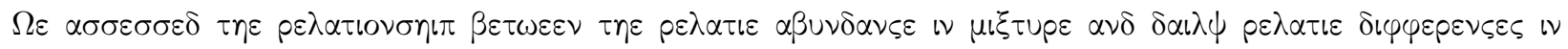

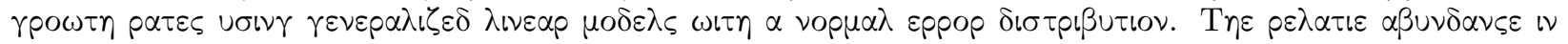

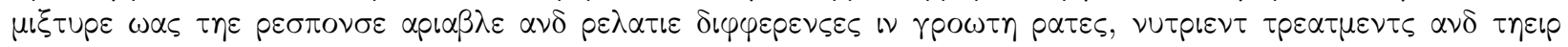

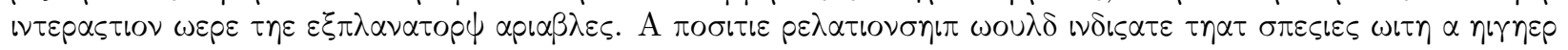

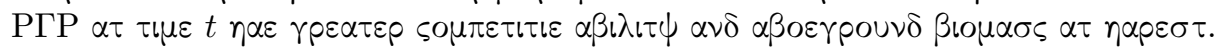

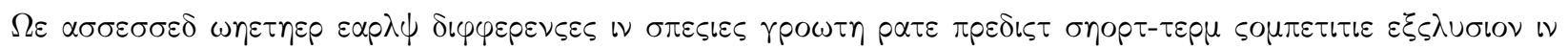

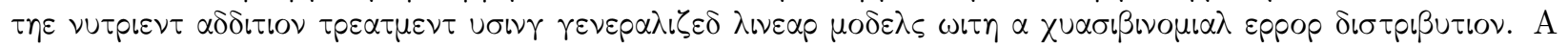

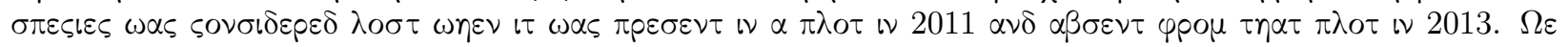

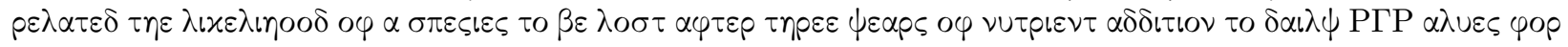

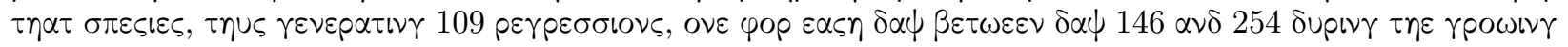

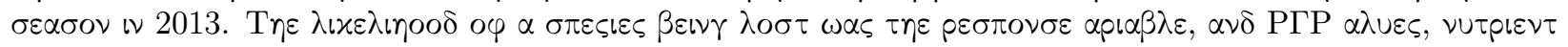

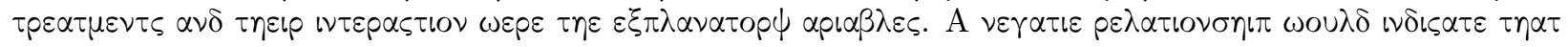

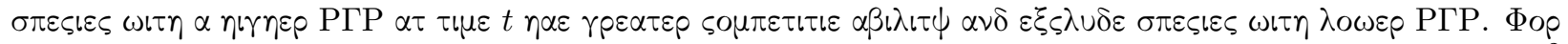

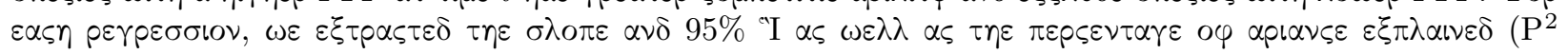
$\alpha \lambda \cup \varepsilon)$.

\section{$P \varepsilon \sigma u \lambda \tau \varsigma$}

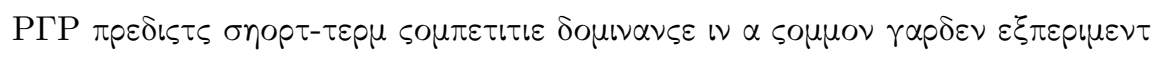

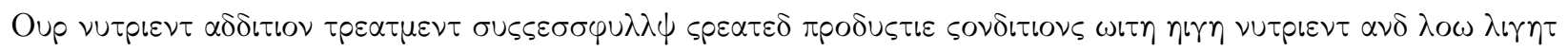

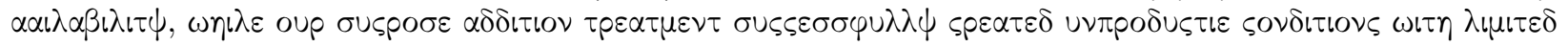

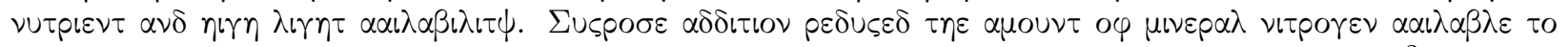

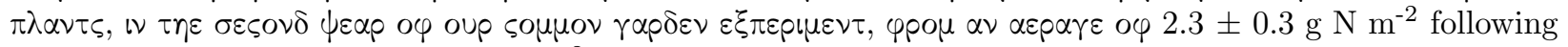
nutrient addition to $0.9 \pm 0.3 \mathrm{~g} \mathrm{~N} \mathrm{~m}^{-2}$ following sucrose addition. It also reduced biomass production in monocultures from $745 \pm 39 \mathrm{~g} \mathrm{~m}^{-2}$ (mean \pm s.e.m.) following nutrient addition to $274 \pm 25 \mathrm{~g} \mathrm{~m}^{-2}$ following sucrose addition $\left(\mathrm{F}_{1,48}=102.34, \mathrm{P}<0.001\right)$ and increased understory light availability measured just before the harvest from $13 \pm 3 \%$ following nutrient addition to $65 \pm 5 \%$ following sucrose addition $\left(\mathrm{F}_{1,48}=54.25\right.$, $\mathrm{P}<0.001$ ) (Table S2).

After two years of treatment, the four parameters of the logistic growth curves used to calculate daily RGR of five perennial grass species growing in monoculture varied across species and nutrient treatments (Fig. S2A; Table S3). As a result, the rankings for species' growth rates changed with both the growing season and nutrient treatment (Fig. S2B). For example, relatively high RGR early in the season was observed for H. lanatus under productive conditions, while A. pratensis had the highest early RGR under unproductive conditions.

We found that early season (day $t=53$ ) relative differences in species growth rates in monoculture were positively associated with relative differences in species biomass at harvest (day 171) in pairwise (Fig. 1A, Fig. S3A) and five-species mixtures (Fig. 1B, Fig. S3B) under both productive and unproductive conditions. The percentage of variance explained was maximum between day $t=53$ and $t=112$. This positive association was observed up to day $t=133$. Relative differences in species' growth rates became smaller as the season progressed until they became negatively associated with differences in species biomass (from day $\mathrm{t}=135$ in the 
year - 14.05.2008) (Fig. S3). The percentage of variance in species biomass at harvest explained by relative differences in species' growth rates during the early stage of the growing season was approximately $50 \%$ under both productive and unproductive conditions for the pairwise mixtures (Fig. S3A) and approximately $60 \%$ under the productive condition and $50 \%$ under the unproductive condition for the five species mixtures (Fig. S3B).

RGR predicts short-term competitive dominance and exclusion in a field experiment

Our nitrogen and combined nitrogen and phosphorus addition treatments created productive conditions and reduced plant diversity while phosphorus addition alone did not significantly affect either productivity or diversity. In the third year of our field experiment, there was a marginally significant interaction between nitrogen and phosphorus addition on biomass production $\left(\mathrm{F}_{1,20}=3.8, \mathrm{P}=0.065\right)$ and plant species richness $\left(\mathrm{F}_{1,20}=3.7, \mathrm{P}=0.069\right)$ (Table $\left.\mathrm{S} 4\right)$. Nitrogen addition increased biomass production from an average of $101 \pm$

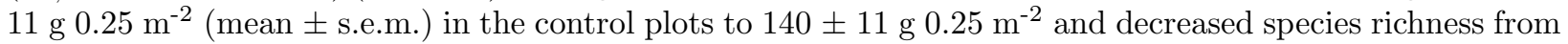
$36 \pm 2$ species $0.25 \mathrm{~m}^{-2}$ to $22 \pm 2$ species $0.25 \mathrm{~m}^{-2}$. In contrast, the levels of biomass production (114 \pm 11 g $\left.0.25 \mathrm{~m}^{-2}\right)$ and species richness $\left(35 \pm 2\right.$ species $\left.0.25 \mathrm{~m}^{-2}\right)$ under phosphorus addition were indistinguishable from those observed in the control plots. The combination of nitrogen and phosphorus addition had a large

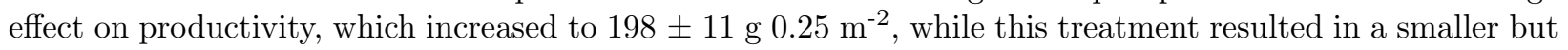
still significant decrease in plant species richness than observed with just nitrogen treatment leading to 28 \pm 2 species $0.25 \mathrm{~m}^{-2}$.

Similar to the results of our common garden experiment, rankings of species growth rates changed with both growing season and nutrient treatments (Fig. S4). We found that the relationship between early season relative differences in species growth rates and relative differences in species biomass varied with both the growing season and nutrient treatments (Fig. 2A, Fig. S5A). The percentage of variance explained was maximum at day 150 in the control $\left(\mathrm{R}^{2}=0.29, \mathrm{~F}_{1,169}=70.1, \mathrm{P}<0.001\right), 146$ with nitrogen addition $\left(\mathrm{R}^{2}=0.35, \mathrm{~F}_{1,169}=89.3, \mathrm{P}<0.001\right), 164$ with phosphorus addition $\left(\mathrm{R}^{2}=0.11, \mathrm{~F}_{1,151}=18.0, \mathrm{P}<0.001\right)$ and 146 with nitrogen and phosphorus addition $\left(\mathrm{R}^{2}=0.26, \mathrm{~F}_{1,151}=53.2, \mathrm{P}<0.001\right)$. When significant, relationships were always positive (Fig. 2A, Fig. S5A). Results based on relative differences in species growth rates calculated between the two first measurements of biomass confirmed that early differences in growth rates predict competitive dominance at harvest except in the phosphorus addition treatment (Fig. S6).

We found that the relationship between early season species growth rate values and the likelihood of loss of a species varied with both the growing season and nutrient treatments (Fig. 2B, Fig. S5B). The percentage of variance explained was maximum at day 146 in the control $\left(\mathrm{R}^{2}=0.05, \mathrm{~F}_{1,118}=2.9, \mathrm{P}=0.11\right), 147$ with nitrogen addition $\left(\mathrm{R}^{2}=0.12, \mathrm{~F}_{1,118}=11.5, \mathrm{P}=0.003\right), 177$ with phosphorus addition $\left(\mathrm{R}^{2}=0.07, \mathrm{~F}_{1,112}\right.$ $=3.6, \mathrm{P}=0.06)$ and 172 with nitrogen and phosphorus addition $\left(\mathrm{R}^{2}=0.11, \mathrm{~F}_{1,118}=11.6, \mathrm{P}=0.001\right)$. Short-term competitive exclusion could only be predicted by early differences in species growth rate under productive conditions (nitrogen and nitrogen \& phosphorus addition) and, when significant, relationships were always negative (Fig. 2B, Fig. S5B). Under unproductive conditions (control and phosphorus addition), short-term competitive exclusion could not be predicted from early differences in growth rate.

\section{Discussion}

Our competition experiment in a common garden shows that early-season differences in species' growth rates in monoculture are good predictors of short-term differences in relative abundance in pairwise and five species mixtures and that predictions were stronger under productive (light-limited) conditions. The species that grew faster early in the season (i.e. H. lanatus and A. pratensis), had the greatest competitive advantage relative to slower-growing species (i.e.A. odoratum, A. elatius and F. rubra). Relative differences in species growth rates became smaller as the growing season progressed until they eventually became negatively associated with differences in species biomass. This switch corresponds to the time at which faster growing species had already reached their maximum growth rate and gradually slowed down while the RGR of slow-growing species was still rising (around day 134 in the year - 13/05/2008). Early differences in species' growth rate also governed short-term competitive outcomes in our semi-natural grassland subjected 
to nutrient addition, thereby extending the results of the common garden experiment to a real-world grassland ecosystem. Together these results indicate that species growing faster during the early stage of the growing season, and thus reducing light availability during this early phase of vegetation growth, had a competitive advantage relative to species that initially grow more slowly.

Addition of nitrogen in our semi-natural grassland ecosystem increased productivity and reduced plant diversity, allowing us to further assess whether differences in species growth rate predict short-term competitive exclusion due to nutrient addition. We found that difference in early season RGR predict short-term competitive exclusion under productive conditions, but not under unproductive conditions. Under productive conditions, the species that grew faster early in the season (e.g. Anemonetrullifolia,Gentiana sino-ornata, andSaussurea nigrescens), competitively excluded initially slower growing species (e.g. Potentillaanserina, Potentillafragarioides, Euphorbiaaltotibetica and Geraniumpylzowianum ). This result suggests that when nutrient limitation is alleviated and productivity is increased, the resulting decline in diversity is partly caused by species that grow fast initially reducing resource availability and outcompeting species that grow more slowly.

Previous studies have shown that under productive conditions, when competition is mainly for light, asymmetric competition causes plant species intercepting more light early in the season to have a disproportionate advantage, leading to competitive exclusion of subordinate species (HautierVojtech et al., 2018, Vojtech et al., 2008, Vojtech et al., 2007, Hautier, 2009, DeMalach et al., 2017). Our study is the first to our knowledge to reveal the critical time during the growing season when exclusion mechanisms act. We show that differences in early season growth rates (day 53 when the growing season starts at ${ }^{\sim}$ day 106 in Zurich and around day 155 when the growing season starts at day 136 in Gansu) provide an explanation of competitive outcomes, thereby serving as a predictor and early signalling of plant competitive abilities. This is because under productive conditions, asymmetric competition leads to increased relative size differences between species early in the season. This early advantage allows fast-growing species to maintain and increase their initial dominant position throughout the growing season, leading to the exclusion of initially slower growing species. Our study is in agreement with earlier studies demonstrating that instantaneous measurements of light obtained early in the season, at the critical time when light becomes limiting for plant growth, were the best predictors of competitive outcomes (Vojtech et al., 2007, Violle et al., 2007).

Our results from the field experiment are based on a subset of the total number of species occurring in the community. Growth rates were derived from the twenty most common species across all treatments, accounting for $85 \pm 10 \%$ of the total aboveground biomass. Our results are therefore most likely conservative because they are restricted to competitive exclusion amongst the twenty-most common species, thereby failing to consider the exclusion of the rarest species, which comprise a large proportion of the total species number and are more susceptible to human disturbances.

Previous studies have shown that the outcome of competition in pairwise mixtures could be best predicted by differences in light intercepting ability in monocultures $\left(I^{*}\right)$ under productive (light-limited) conditions and by differences in nutrient uptake ability in monocultures $\left(R^{*}\right)$ under unproductive conditions (Dybzinski and Tilman, 2007, Vojtech et al., 2007, HautierVojtech et al., 2018). However, in real-world ecosystems that encompass nutrient gradients, both forms of competition are likely to act at the same time, with light competition becoming more important as nutrient competition lessens. Our results are consistent with the resource ratio hypothesis envisaging a trade-off between competition for light under fertile conditions and for nutrients under less fertile conditions. Under fertile conditions, species growing faster early in the season have a competitive advantage over initially slower-growing species (consistent with them being better competitors for light). This relationship between RGR and competitive success weakens under less fertile conditions (compare fertile conditions with added nitrogen from less fertile conditions without added nitrogen in Figures 1, 2 S3, S5 and S6). However, we would expect, based on earlier work (Tilman and Wedin 1991, Wedin and Tilman 1993), that slow-growing species with the lowest $R *$ for soil resources would dominate the community in the long-term (a long-term outcome that we were not able to assess in our relatively short-term study). This would require that slow growing species do not entirely disappear from the landscape. 
Our study thus suggests that human activities that increase the availability of nutrients to ecosystems will likely further reduce plant diversity in the future by benefitting initially fast-growing species. In contrast, management practices directed towards reducing the growth of fast-growing species early in the season should help efforts to protect and restore biodiversity in an increasingly human-dominated world. For example, parasitic plants such as Rhinanthus species can restore biodiversity in productive grasslands (DiGiovanni et al., 2017, Bardgett et al., 2006, Pywell et al., 2004, Bullock and Pywell, 2005). A potential mechanism is through the reduction of the biomass of competitively dominant grasses (Davies et al., 1997, Ameloot et al., 2005), simply because the parasite reduces host resources leading to a reduction in host growth rate and future resource uptake (Hautier et al., 2010). Our results suggest that Rhinanthus species could be particularly effective because they cancel out the initial advantage of fast-growing species early in the season thus limiting the exclusion of slower-growing species. Adjusting the timing and frequency of cutting could also be used as a restoration tool in nutrient-rich grasslands. For example, a higher frequency of cutting that alters the structure of the canopy layer can reduce asymmetric competition for light and the initial advantage of fast growing species, giving slow growing species more equal chances to compete for the limiting resources (HautierVojtech et al., 2018, Talle et al., 2018). On the other hand, multiple cuts per season may reduce the number of flowering plant and seeds that impact pollination, food for plant-feeding insects, seed recruitment and nesting sites for birds (Plantureux et al., 2005). Our results suggest that an early cut combined with a late cut in the season could constitute a good management strategy. While an early cut reduces competition for light and the competitive dominance of fast-growing species, thus promoting diversity, a late cut provides nesting sites and allows plants to produce flowers and mature seeds. Additionally, cutting with subsequent haying has the advantage of removing plant biomass and excess accumulated nutrients in the soils, allowing the subsequent recovery of diversity (Storkey et al., 2015). Alternatively, low-diversity stable state could persist even after decades of cessation of nutrient enrichment if biomass is not removed and recycled within the system (Tilman and Isbell, 2015, Isbell et al., 2013).

\section{Acknowledgments}

We thank Hossein Moradi, Melanie Aardalsbakke, Eva Vojtech and Daniel Trujillo for field assistance and Forest Isbell and Adam Clark for useful discussions on the relationship between RGR and $R * / I *$. Pengfei Zhang was funded by the azi.cn site by the Key Program of the National Natural Science Foundation of China (No. 41430749) and supported by Chinese Scholarship Council (CSC) joint PhD scholarship. Yann Hautier was funded by Swiss National Foundation grant 3100A0-107572 to Andy Hector.

\section{Author contributions}

Yann Hautier and Andy Hector conceived and designed the experiment at the University of Zurich and Pengfei Zhang, Xiaolong Zhou and Guozhen Du at Lanzhou University. Yann Hautier performed the experiment at the University of Zurich and Pengfei Zhang, Xiaolong Zhou and Zhi Guo at Lanzhou University. Pengfei Zhang and Yann Hautier analyzed the data with input from all authors. Pengfei Zhang and Yann Hautier wrote the manuscript with inputs from all authors.

\section{Data accessibility}

Data will be made publicly available upon acceptance on the Dryad Digital Repository.

\section{References}

Ameloot, E., Verheyen, K. \& Hermy, M. (2005) Meta-analysis of standing crop reduction by Rhinanthus spp. and its effect on vegetation structure. Folia Geobotanica,40, 289-310.

Bardgett, R. D., Smith, R. S., Shiel, R. S., Peacock, S., Simkin, J. M., Quirk, H. \& Hobbs, P. J. (2006) Parasitic plants indirectly regulate below-ground properties in grassland ecosystems. Nature, 439, 969-972.

Borer, E. T., Seabloom, E. W., Gruner, D. S., Harpole, W. S., Hillebrand, H., Lind, E. M., Adler, P. B., Alberti, J., Anderson, T. M., Bakker, J. D., Biederman, L., Blumenthal, D., Brown, C. S., Brudvig, L. A., Buckley, Y. M., Cadotte, M., Chu, C., Cleland, E. E., Crawley, M. J., Daleo, P., Damschen, E. I., Davies, 
K. F., DeCrappeo, N. M., Du, G., Firn, J., Hautier, Y., Heckman, R. W., Hector, A., HilleRisLambers, J., Iribarne, O., Klein, J. A., Knops, J. M. H., La Pierre, K. J., Leakey, A. D. B., Li, W., MacDougall, A. S., McCulley, R. L., Melbourne, B. A., Mitchell, C. E., Moore, J. L., Mortensen, B., O'Halloran, L. R., Orrock, J. L., Pascual, J., Prober, S. M., Pyke, D. A., Risch, A. C., Schuetz, M., Smith, M. D., Stevens, C. J., Sullivan, L. L., Williams, R. J., Wragg, P. D., Wright, J. P. \& Yang, L. H. (2014) Herbivores and nutrients control grassland plant diversity via light limitation. Nature, 508, 517-520.

Bullock, J. M. \& Pywell, R. F. (2005) Rhinanthus: A tool for restoring diverse grassland? Folia Geobotanica, 40, 273-288.

Chesson, P. (2000) Mechanisms of maintenance of species diversity. Annual Review of Ecology and Systematics, 31, 343-366.

Davies, D. M., Graves, J. D., Elias, C. O. \& Williams, P. J. (1997) The impact of Rhinanthus spp. on sward productivity and composition: Implications for the restoration of species-rich grasslands. Biological Conservation, 82,87-93.

DeMalach, N., Zaady, E. \& Kadmon, R. (2017) Light asymmetry explains the effect of nutrient enrichment on grassland diversity. Ecology Letters, 20, 60-69.

DiGiovanni, J. P., Wysocki, W. P., Burke, S. V., Duvall, M. R. \& Barber, N. A. (2017) The role of hemiparasitic plants: influencing tallgrass prairie quality, diversity, and structure. Restoration Ecology, 25, 405-413.

Dybzinski, R. \& Tilman, D. (2007) Resource use patterns predict long-term outcomes of plant competition for nutrients and light. American Naturalist, 170,305-318.

Erisman, J. W., Sutton, M. A., Galloway, J., Klimont, Z. \& Winiwarter, W. (2008) How a century of ammonia synthesis changed the world. Nature Geoscience,1, 636-639.

Fay, P. A., Prober, S. M., Harpole, W. S., Knops, J. M. H., Bakker, J. D., Borer, E. T., Lind, E. M., MacDougall, A. S., Seabloom, E. W., Wragg, P. D., Adler, P. B., Blumenthal, D. M., Buckley, Y. M., Chu, C., Cleland, E. E., Collins, S. L., Davies, K. F., Du, G., Feng, X., Firn, J., Gruner, D. S., Hagenah, N., Hautier, Y., Heckman, R. W., Jin, V. L., Kirkman, K. P., Klein, J., Ladwig, L. M., Li, Q., McCulley, R. L., Melbourne, B. A., Mitchell, C. E., Moore, J. L., Morgan, J. W., Risch, A. C., Schütz, M., Stevens, C. J., Wedin, D. A. \& Yang, L. H. (2015) Grassland productivity limited by multiple nutrients. Nature Plants, 1, 15080 .

Harpole, W. S., Sullivan, L. L., Lind, E. M., Firn, J., Adler, P. B., Borer, E. T., Chase, J., Fay, P. A., Hautier, Y., Hillebrand, H., MacDougall, A. S., Seabloom, E. W., Bakker, J. D., Cadotte, M. W., Chaneton, E. J., Chu, C., Hagenah, N., Kirkman, K., La Pierre, K. J., Moore, J. L., Morgan, J. W., Prober, S. M., Risch, A. C., Schuetz, M. \& Stevens, C. J. (2017) Out of the shadows: multiple nutrient limitations drive relationships among biomass, light and plant diversity. Functional Ecology,31, 1839-1846.

Hautier, Y. (2009) Mechanisms of maintenance and restoration of plant diversity . University of Zurich, Zurich, Switzerland.

Hautier, Y., Hector, A., Vojtech, E., Purves, D. \& Turnbull, L. A. (2010) Modelling the growth of parasitic plants. Journal of Ecology, 98, 857-866.

Hautier, Y., Isbell, F., Borer, E. T., Seabloom, E. W., Harpole, W. S., Lind, E. M., MacDougall, A. S., Stevens, C. J., Adler, P. B., Alberti, J., Bakker, J. D., Brudvig, L. A., Buckley, Y. M., Cadotte, M., Caldeira, M. C., Chaneton, E. J., Chu, C. J., Daleo, P., Dickman, C. R., Dwyer, J. M., Eskelinen, A., Fay, P. A., Firn, J., Hagenah, N., Hillebrand, H., Iribarne, O., Kirkman, K. P., Knops, J. M. H., La Pierre, K. J., McCulley, R. L., Morgan, J. W., Partel, M., Pascual, J., Price, J. N., Prober, S. M., Risch, A. C., Sankaran, M., Schuetz, M., Standish, R. J., Virtanen, R., Wardle, G. M., Yahdjian, L. \& Hector, A. (2018) Local loss and spatial homogenization of plant diversity reduce ecosystem multifunctionality. Nature Ecology \& Evolution, 2, 50-56. 
Hautier, Y., Niklaus, P. A. \& Hector, A. (2009) Competition for Light Causes Plant Biodiversity Loss After Eutrophication. Science, 324, 636-638.

Hautier, Y., Seabloom, E. W., Borer, E. T., Adler, P. B., Harpole, W. S., Hillebrand, H., Lind, E. M., MacDougall, A. S., Stevens, C. J., Bakker, J. D., Buckley, Y. M., Chu, C., Collins, S. L., Daleo, P., Damschen, E. I., Davies, K. F., Fay, P. A., Firn, J., Gruner, D. S., Jin, V. L., Klein, J. A., Knops, J. M. H., La Pierre, K. J., Li, W., McCulley, R. L., Melbourne, B. A., Moore, J. L., O'Halloran, L. R., Prober, S. M., Risch, A. C., Sankaran, M., Schuetz, M. \& Hector, A. (2014) Eutrophication weakens stabilizing effects of diversity in

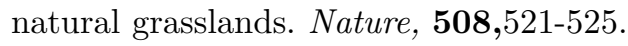

Hautier, Y., Tilman, D., Isbell, F., Seabloom, E. W., Borer, E. T. \& Reich, P. B. (2015) Anthropogenic environmental changes affect ecosystem stability via biodiversity.Science, 348, 336-340.

Hautier, Y., Vojtech, E. \& Hector, A. (2018) The importance of competition for light depends on productivity and disturbance Ecology and Evolution,2018;1-7 .

Hector, A., Hautier, Y., Saner, P., Wacker, L., Bagchi, R., Joshi, J., Scherer-Lorenzen, M., Spehn, E. M., Bazeley-White, E., Weilenmann, M., Caldeira, M. C., Dimitrakopoulos, P. G., Finn, J. A., Huss-Danell, K., Jumpponen, A., Mulder, C. P. H., Palmborg, C., Pereira, J. S., Siamantziouras, A. S. D., Terry, A. C., Troumbis, A. Y., Schmid, B. \& Loreau, M. (2010) General stabilizing effects of plant diversity on grassland productivity through population asynchrony and overyielding. Ecology, 91, 2213-2220.

Hutchinson, G. E. (1957) Population studies: Animal ecology and demography. Cold Spring Harbor Symposia on Quantitative Biology, 22, 415-427.

Isbell, F., Craven, D., Connolly, J., Loreau, M., Schmid, B., Beierkuhnlein, C., Bezemer, T. M., Bonin, C., Bruelheide, H., de Luca, E., Ebeling, A., Griffin, J. N., Guo, Q., Hautier, Y., Hector, A., Jentsch, A., Kreyling, J., Lanta, V., Manning, P., Meyer, S. T., Mori, A. S., Naeem, S., Niklaus, P. A., Polley, H. W., Reich, P. B., Roscher, C., Seabloom, E. W., Smith, M. D., Thakur, M. P., Tilman, D., Tracy, B. F., van der Putten, W. H., van Ruijven, J., Weigelt, A., Weisser, W. W., Wilsey, B. \& Eisenhauer, N. (2015) Biodiversity increases the resistance of ecosystem productivity to climate extremes. Nature, 526, 574-U263.

Isbell, F., Tilman, D., Polasky, S., Binder, S. \& Hawthorne, P. (2013) Low biodiversity state persists two decades after cessation of nutrient enrichment. Ecology Letters,16, 454-460.

Lauber, K. \& Wagner, G. (2001)Flora Helvetica; Flore Illustrée de Suisse. Haupt.

McCullagh, P. \& Nelder, J. A. (1989) Generalized Linear Models. Chapman and Hall, London.

Midolo, G., Alkemade, R., Schipper, A. M., Benitez-Lopez, A., Perrings, M. P. \& De Vries, W. (2018) Impacts of nitrogen addition on plant species richness and abundance: A global meta-analysis. Global Ecology and Biogeography , 1-16.

Paine, C. E. T., Marthews, T. R., Vogt, D. R., Purves, D., Rees, M., Hector, A. \& Turnbull, L. A. (2012) How to fit nonlinear plant growth models and calculate growth rates: an update for ecologists. Methods in Ecology and Evolution,3, 245-256.

Petermann, J. S., Fergus, A. J. F., Turnbull, L. A. \& Schmid, B. (2008) Janzen-Connell effects are widespread and strong enough to maintain diversity in grasslands.Ecology, 89, 2399-2406.

Pinheiro, J. C. \& Bates, D. M. (2000) Mixed-Effects Models in S and S-Plus. Spinger-Verlag: New York .

Plantureux, S., Peeters, A. \& McCracken, D. (2005) Biodiversity in intensive grasslands: Effect of management, improvement and challenges. Agronomy Research,3, 153-164.

Pywell, R. F., Bullock, J. M., Walker, K. J., Coulson, S. J., Gregory, S. J. \& Stevenson, M. J. (2004) Facilitating grassland diversification using the hemiparasitic plant Rhinanthus minor. Journal of Applied Ecology, 41,880-887. 
R Development Core Team (2018) R: A language and environment for statistical computing. R Foundation for Statistical Computing, Vienna, Austria.

Ren, H., Chen, Y.-C., Wang, X. T., Wong, G. T. F., Cohen, A. L., DeCarlo, T. M., Weigand, M. A., Mii, H.-S. \& Sigman, D. M. (2017) 21st-century rise in anthropogenic nitrogen deposition on a remote coral reef. Science, 356,749-752.

Sinha, E., Michalak, A. M. \& Balaji, V. (2017) Eutrophication will increase during the 21st century as a result of precipitation changes. Science, 357, 405-408.

Soons, M. B., Hefting, M. M., Dorland, E., Lamers, L. P. M., Versteeg, C. \& Bobbink, R. (2017) Nitrogen effects on plant species richness in herbaceous communities are more widespread and stronger than those of phosphorus. Biological Conservation, 212, 390-397.

Storkey, J., Macdonald, A. J., Poulton, P. R., Scott, T., Kohler, I. H., Schnyder, H., Goulding, K. W. T. \& Crawley, M. J. (2015) Grassland biodiversity bounces back from long-term nitrogen addition. Nature, 528, 401-+.

Talle, M., Deak, B., Poschlod, P., Valko, O., Westerberg, L. \& Milberg, P. (2018) Similar effects of different mowing frequencies on the conservation value of semi-natural grasslands in Europe. Biodiversity and Conservation, 27,2451-2475.

Tilman, D. (1980) Resources: a graphical-mechanistic approach to competition and predation.American Naturalist, 116, 362-393.

Tilman, D. (1982) Resource competition and community structure. Princeton University Press, Princeton.

Tilman, D. \& Isbell, F. (2015) BIODIVERSITY Recovery as nitrogen declines. Nature, 528,336-337.

Violle, C., Lecoeur, J. \& Navas, M. L. (2007) How relevant are instantaneous measurements for assessing resource depletion under plant cover? A test on light and soil water availability in 18 herbaceous communities. Functional Ecology,21, 185-190.

Vojtech, E., Loreau, M., Yachi, S., Spehn, E. M. \& Hector, A. (2008) Light partitioning in experimental grass communities. Oikos, 117, 1351-1361.

Vojtech, E., Turnbull, L. A. \& Hector, A. (2007) Differences in Light Interception in Grass Monocultures Predict Short-Term Competitive Outcomes under Productive Conditions. PLoS ONE, 2, e499.

Zhang, P. F., Zhou, X. L., Li, J. Y., Guo, Z. \& Du, G. Z. (2015) Space resource utilisation: a novel indicator to quantify species competitive ability for light.Scientific Reports, $\mathbf{5}$.

Zhou, X., Liu, X., Zhang, P., Zhi, G. \& Du, G. (2018) Increased community compositional dissimilarity alleviates species loss following nutrient enrichment at large spatial scales. Journal of Plant Ecology .

Zhou, X. L., Guo, Z., Zhang, P. F., Li, H. L., Chu, C. J., Li, X. L. \& Du, G. Z. (2017) Different categories of biodiversity explain productivity variation after fertilization in a Tibetan alpine meadow community. Ecology and Evolution, 7, 3464-3474.

\section{Figure legends}

Figure 1. Common garden. Early-season relative differences in species growth rates in monoculture $\left(\mathrm{RGR}_{t \mathrm{ij}}, t=53\right)$ predict relative differences in species biomass $\left(B_{\mathrm{ij}}\right)$ at harvest date $(t=171)$ in $\left.\mathrm{A}\right)$ ten pairwise mixtures of five species and B) ten combination of pairs of species within five species mixtures under productive (left panels) and unproductive (right panels) conditions. Relative differences were calculated as the natural logarithm of the ratio between pairs of species in a treatment combination. $A l=$ Alopecurus pratensis,$A n=$ Anthoxanthum odoratum,$A r=$ Arrhenatherum elatius,$F=$ Festuca rubra,$H=$ Holcus lanatus. The grey region indicates the $95 \%$ confidence interval around the regression. 
Figure 2. Field experiment. RGR predicts competitive dominance and exclusion. A) Early-season relative differences in species growth rates in a nutrient addition combination $\left(\mathrm{RGR}_{t_{\mathrm{ij}}}\right)$ predict relative differences in species biomass in pairs of species combinations of the respecting nutrient addition combination $\left(B_{\mathrm{ij}}\right)$ at harvest date $(t=213-221)$. B) Early season growth rate in a nutrient addition combination (RGR) predicts the likelihood of a species to be lost in the respecting nutrient addition combination (Likelihood of loss; a species was considered lost when it was present in a plot in 2011 and absent from that plot in 2013). Dots in Fig. B indicate RGR at day $t$ of species that were lost (1) or not lost (0). Results are shown for the day $t$ at which the percentage of variation explained by the regression $\left(\mathrm{R}^{2}\right)$ was maximum for each nutrient addition combination (see Fig. S2). Within each graph (A, B) fertile conditions with added N (right) are separated from less fertile conditions without added N (left). The grey region indicates the $95 \%$ confidence interval around the regression.

\section{Figure 1}

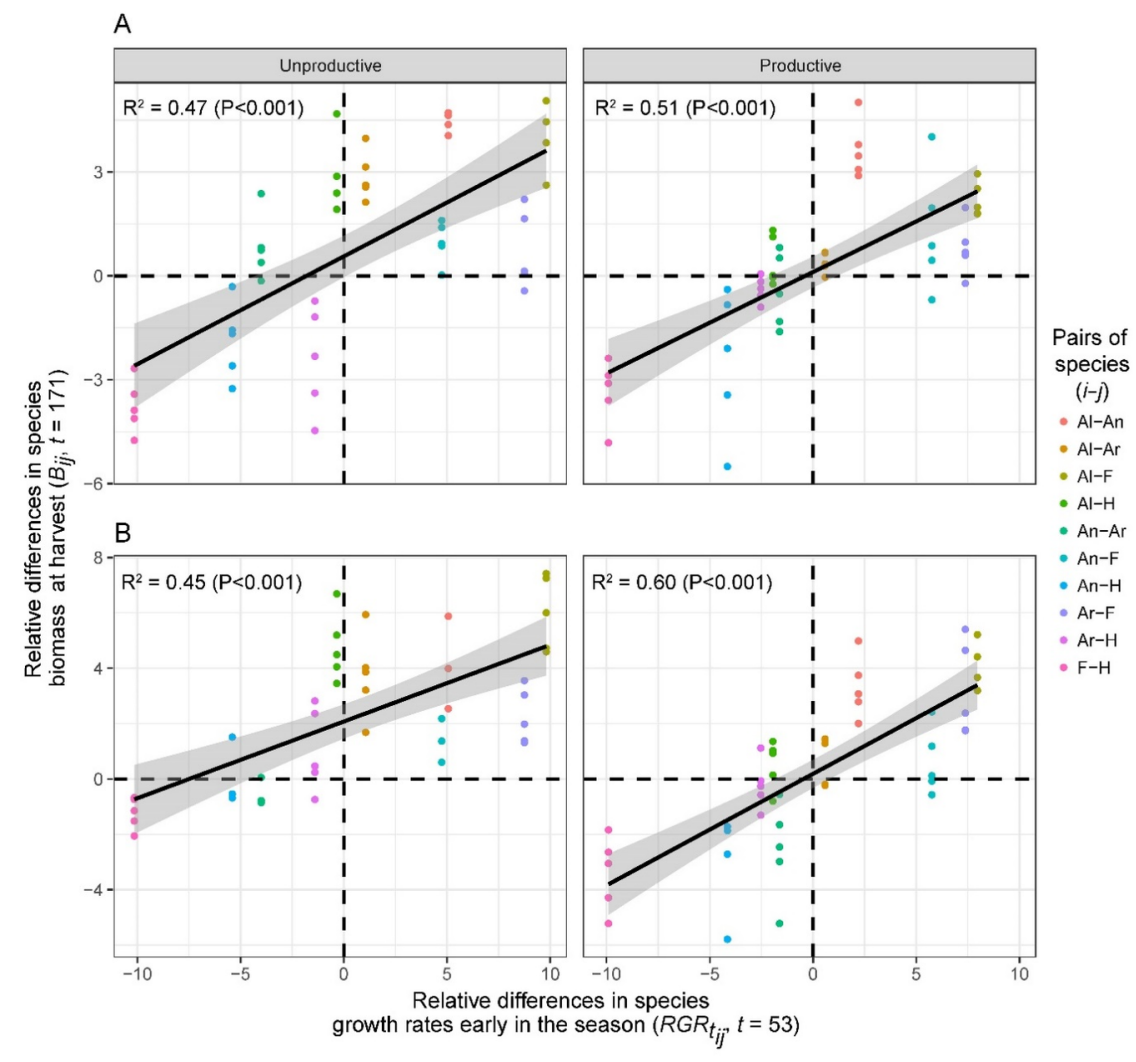

Figure 2 

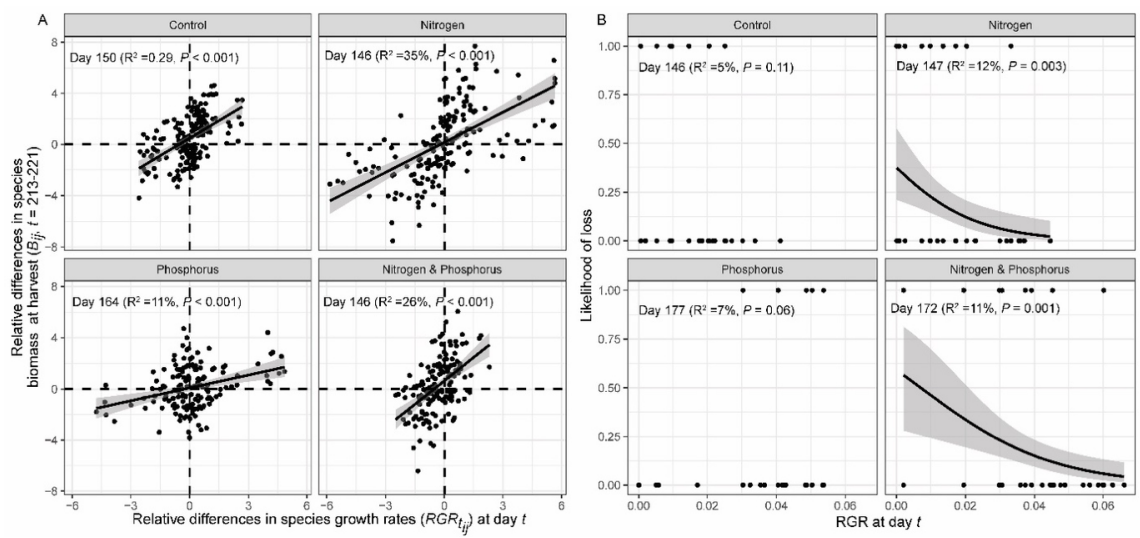